\title{
Ocean Observation Technologies: A Review
}

\author{
Mingwei Lin ${ }^{1}$ and Canjun Yang ${ }^{1,2,3^{*}}$
}

\begin{abstract}
Covering about three quarters of the surface area of the earth, the ocean is a critical source of sustenance, medicine, and commerce. However, such vast expanse in both surface area and depth, presents myriad observing challenges for researchers, such as corrosion, attenuation of electromagnetic waves, and high pressure. Ocean observation technologies are progressing from the conventional single node, static and short-term modalities to multiple nodes, dynamic and long-term modalities, to increase the density of both temporal and spatial samplings. Although people's knowledge of the oceans has been still quite limited, the contributions of many nations cooperating to develop the Global Ocean Observing System (GOOS) have remarkably promoted the development of ocean observing technologies. This paper reviews the typical observing technologies deployed from the sea surface to the seafloor, and discusses the future trend of the ocean observation systems with the docking technology and sustained ocean energy.
\end{abstract}

Keywords: Ocean observation, Observatory, Sampling, Underwater, Ocean energy, AUV, Docking, Recharging

\section{Introduction}

There is increasing concern about global climate change and its regional impacts. According to the latest survey, sea level is rising at an accelerating rate of approximately $3.4 \mathrm{~mm}$ per year, Arctic ice coverage is shrinking and high latitude areas are getting warming rapidly [1]. The oceans are integral to life on the earth, climate regulation, and carbon cycles. Understanding even accurately predicting the ocean processes and atmosphere changes are vital for using ocean resources responsibly and sustainably. Hardly anyone doubts that the present ocean observation data were sparsely sampled temporally and spatially. Although technology advances are responding to these challenges, the efforts so far have been incremental and inadequate.

Most of our early knowledge about the interior of the ocean came from the research or merchant ship measurements, which were gathered more in summer and few in the remote but climatically important Southern Ocean.

\footnotetext{
*Correspondence: ycj@zju.edu.cn

1 State Key Laboratory of Fluid Power and Mechatronic Systems, Zhejiang University, Hangzhou 310027, China

Full list of author information is available at the end of the article
}

Even with the development of satellites, much of our enquiry has been restricted by an opaque surface of the oceans. A notable exception was that since 1978 Japan had been developing cabled seafloor observing systems to monitor seafloor physical features because of its special location, which is near the plate boundaries where catastrophic earthquakes and tsunamis occur periodically [2]. To match the increasing requirements from the scientific community, many international projects and initiatives have been operated since the early 1990s. The Tropical Atmosphere Ocean (TAO)/Triton mooring array, which was completed in 1994, was successfully fielded to span the Pacific Ocean with immediately available date to forecast El Nino phenomena up to a year ahead of their peak [3]. Additionally, researchers established the World Ocean Circulation Experiment (WOCE) in 1990 [4, 5], setting out to develop models useful for predicting climate change and finding methods for determining long-term changes in the ocean circulation. The first Argo floats were deployed to systematically monitor the state of the global oceans together in 1999, with Jason satellites. In the past two decades, the development of sustained, dynamic and multi-node observatories was paid much attention from the oceanographic researchers, providing near-real-time or real-time series to monitor changes in physical, chemical, biological and

\section{Springer Open}

(c) The Author(s) 2020. This article is licensed under a Creative Commons Attribution 4.0 International License, which permits use, sharing, adaptation, distribution and reproduction in any medium or format, as long as you give appropriate credit to the original author(s) and the source, provide a link to the Creative Commons licence, and indicate if changes were made. The images or other third party material in this article are included in the article's Creative Commons licence, unless indicated otherwise in a credit line to the material. If material is not included in the article's Creative Commons licence and your intended use is not permitted by statutory regulation or exceeds the permitted use, you will need to obtain permission directly from the copyright holder. To view a copy of this licence, visit http://creativeco mmons.org/licenses/by/4.0/. 
geologic features. The obtained contributions and experience had laid a strong base for the development of the Global Ocean Observing System (GOOS) [6], which constitute the ocean segment of Global Earth Observing System of Systems (GEOSS) [7]. Japan, the USA, Canada and Europe are present major participants, but other countries which have great potential to make contributions, such as China, are now joining in the cooperation.

This paper makes no claim to completeness but is instead intended to describe typical ocean observation technologies ranging from the sea surface to the seafloor, giving readers the background required to form their opinions of the usefulness of each technology, as well as a blueprint of the future ocean observation systems, which are support by the docking technologies and sustained ocean energy.

\section{Sea Surface Observation Technologies 2.1 Moored Buoys}

Observing the surface meteorology by moored buoys has a long history and the present engineering designs are mature and have benefited from decades of field experience. The Tropical Ocean Global Atmosphere (TOGA) program was initialized in 1985 with contributions from 16 nations to collect observations of the tropical atmosphere and study the influence of the tropical atmosphere/ ocean system [8]. The moored buoys were one of the most important technologies to predict El Nino-Southern Oscillation (ENSO) phenomenon, and constructed a cost-effective Autonomous Temperature Line Acquisition System (ATLAS) capable of telemetering its data in real time by the Argo satellite system [9]. TOGA, which is known as the TAO array now, is the counterpart of the two basin-scaled observing systems in the tropical Pacific Ocean. Arrays in the Atlantic Ocean (PIRATA) and Indian Ocean (RAMA) are also providing sustained data for climate research.

Air-sea fluxes of heat, freshwater, and momentum are essential components of the ocean studies aimed at improving people's understanding of the coupling between the ocean and the atmosphere. The equipped instruments or sensors on the buoy/mooring systems tend to be customized to each especial application according to the differences in the deployed depth, sea conditions and service intervals. For most cases, the collected data of moored buoys used for establishing accurate air-sea coupling models should include sea surface temperature, surface wind speed and direction, barometric pressure, currents, air temperature and relative humidity, solar shortwave/longwave radiation and precipitation (rain) [10]. Although more equipped meteorological sensors on the buoys and moorings contribute more to the study of the oceans, the cost is a non-ignorable factor in the designs.

The size and shape have great impacts on the performance of a moored buoy system. A mooring design typically proceeds by firstly determining the payload requirements and subsequently designing a buoy that can house payload with good stability for implement and maintenance. Typical construction of a meteorological buoy contains a floating buoy element held in place by a mooring system. It can also have autonomous profiles for sampling water column by rising and sinking along the mooring cable with physical sensors to measure ambient conductivity, temperature and depth (CTD) [11]. The Air-Sea Interaction Meteorological (ASIMET) mooring buoy system, which was developed by Woods Hole Oceanographic Institute (WHOI), has two identical and independent sensor suites to ensure a complete surface meteorological time series (over $98 \%$ of the time) and support examination of drifts and possible degradation of sensors [12, 13]. To achieve reliable observations in extreme environments, such Arctic, the developers proposed a purpose-built detection mooring to survive cold temperature, achieving measurement of upper water column stratification and hear content through the fall up to time of freeze-up in ice-covered sea [14].

Typical floating buoys can be classified into four types [15]. Toroidal and discus types have shallow drafts and large water-plane areas and are relatively easy to moor. Sphere-type buoys have intermediate aspect ratios with small volume to handle, and they are usually selected as marker buoys because of the available and simple steel spheres. Spar buoys have large drafts and small waterplane areas. If spar buoys are large enough, their motion can be nearly decoupled from the sea surface. Whatever the aspect ratio of the floating buoy is, most of them are designed to have axisymmetric shape for fabrication convenience. The design criteria of moorings are often the result of compromises considering the factors of deployment environment, cost and payload. The compliance provided by the mooring determines its response to waves and sea level change, and thus needs to be carefully designed to avoid highly repetitive motion and excessive fatigue damage. Three typical moorings are catenary (chain), semi-taut and slack types [16-18], as shown in Figure 1.

Chain moorings can be regarded as the simplest type to design and install because of their low-cost materials and optional anchor types. Despite a good tolerance to depth changes, the design approach of chain moorings in deeper water $(>100 \mathrm{~m})$ becomes more complicated since the surface wind or current would induce the horizontal forcing acting on the anchor. Semi-taut moorings have adaptive compliance, which is provided by the elasticity 


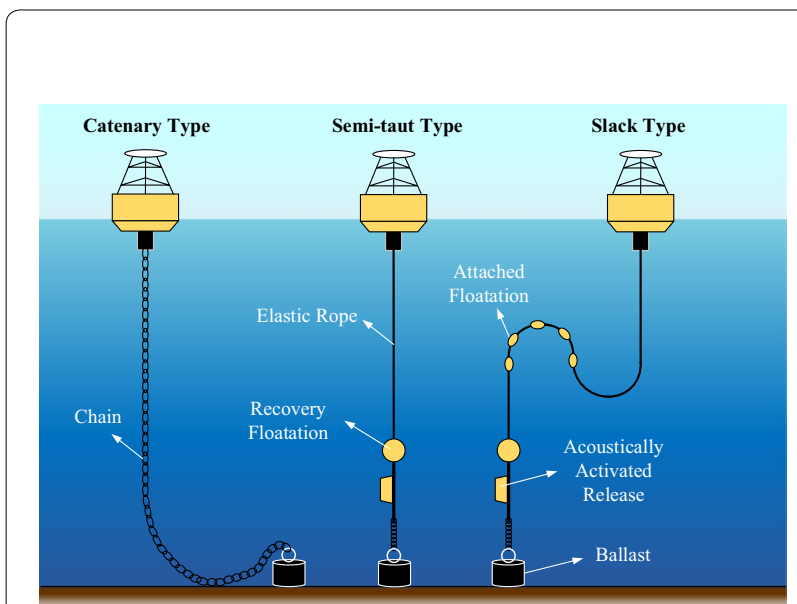

Figure 1 Three typical moorings

of the mooring string elements (nylon, polyester, etc.), and thus this type of moorings can be deployed in a deeper water $(>500 \mathrm{~m})$ with better environmental suitability. Differently, the compliance of slack-type moorings does not depend completely on the elasticity of the mooring string. The other part of the compliance is provided by creating a " $\mathrm{S}$ " curve in the geometry of the mooring string with attached floatation on it. In general, an acoustically activated release should be mounted near the anchor, especially for deep moorings, in order to recover the mooring string with reduced lifting force by the surface vessel.

Deep sea mooring with more sensors, such as seacurrent meters and cameras, would be one of the future objectives of the moored buoy program [19], but the development of the virtual mooring is more promising because of its much lower cost, more flexible locations, and ease of deployment. One should note that the features of the atmosphere and ocean variations cannot be measured only by the moored meteorological buoys. Assimilation can combine observations with detailed computer models and ensure that the results agree with the fundamental physical laws that govern ocean dynamics. Thus, data assimilation with a numerical model is useful to prediction of the climate change and is still the important direction for the future study.

\subsection{Drifters}

The U.S. Costal Dynamics Experiment (CODE) is a multi-institutional examination of costal circulation [20]. The major objective of this program was to observe the response of costal water to wind forcing. The drifters, also referred to as drifting buoys, were the essential component of CODE. The Lagrangian drifters [21], which were deployed by Global Drifter Program (GDP), have

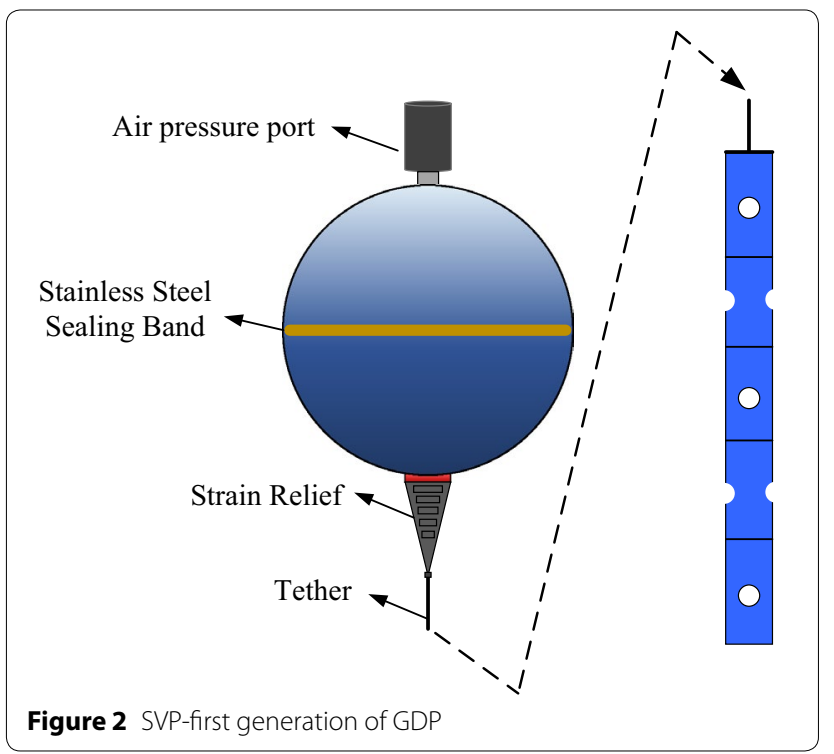

been observing essential climate variables since 1979 . Note that the term Lagrangian, which usually refers to the description of the trajectories of a system of particles from their position and time derivatives, here refers to the water-following capability, that is, the capability to follow a volume of water at the sea surface with minimal slippage. The long-term goals of the GDP are to keep at least 1250 in situ Lagrangian drifters with a nominal observation density of $5 \times 5$ [22], and achieve near-realtime data telemetering for better understanding of most oceanic mesoscale features. The typical measurement accuracy of the ocean currents for Lagrangian drifters is of approximately $0.9 \mathrm{~cm} / \mathrm{s}$ when the wind speed is lower than $10 \mathrm{~m} / \mathrm{s}$ [23].

A typical GDP drifter consists of a surface float attached by a tether to a holey-sock drogue (sea anchor) at a nominal depth of $15 \mathrm{~m}$. To avoid repetition, the detailed design approach of drifters shall not be given here, and it can refer to Ref. [24]. The drifters are a kind of low-cost oceanic platforms and can be largely deployed, providing intensive coverage within a relatively small region. In the development process of drifters, different functions (sensors) were gradually added to these platforms. The Surface Velocity Program (SVP) was the first generation of the GDP and played an important role in the TOGA program, as shown in Figure 2. The SVP drifters were the simplest version of drifters, which can only measure sea surface temperature and ocean currents. With additional sensors, such as barometers, conductometers and sonic anemometers, the performance of the drifters can be enhanced further to adapt to different applications. The major contributions of commonly-measured variables (combinations) are shown in Table 1. 
Table 1 Roles of GDP data

\begin{tabular}{ll}
\hline Variable & Contribution \\
\hline Sea surface temperature (SST) & Validate and calibrate satellite SST [25] \\
Sea surface pressure (SSP) & Assess climate and predict numerical weather [26] \\
Subsurface temperature, air pressure and wind & Track the tropical cyclone [27] \\
Ocean currents & Assimilate oceanic forecasting [28]
\end{tabular}

Indeed, the existing drifters were made of much plastics, which are convenient and economical for fabrication but difficult to biodegrade. Thus, biodegradable drifters might be a future trend for GDP to avoid ocean pollution [29]. Moreover, a compact size, ease of logistics and higher reliability under different sea states without affecting the water-following capabilities are also the future trend of the drifters. Despite the measurement of sea surface velocity, the sparsely sampled data are difficult to assimilate in ocean circulation models. There are various ways for improvements. For instance, if we can measure the velocity shear in the upper ocean in a global scale, the abundant data can not only facilitate assimilation in oceanic models, but also help gain a much deeper understanding of the physics of the mixed layer. To sum up, the densely spatio-temporal sampling of ocean variables using cost-effective, compact, eco-friendly and wellperformed drifters is the future trend that oceanographic researchers are going to contribute to.

\subsection{Space-borne Sensors}

Remote sensing with space-borne sensors is essential for global ocean observation systems. Through these sensors, a majority of sea surface geophysical parameters can be directly or indirectly gained, such as sea surface temperature, wave height, salinity, etc. Different from many in-situ observatories (such as moored buoys, drifters, and ships), oceanographic satellites can provide observations on a global scale, not only restricted to regional, meso or other relatively small scales. Figure 3 demonstrates the sketch diagram of observing by remote sensing.

The era of satellite-based remote sensing started in 1957 when the world's first artificial satellite Sputnik-1 launched and returned the first view of our planet's surface and atmosphere [30]. Since then, considerable technology advances in satellites have been made, especially in the field of space-borne sensors. The operational principle of most space-borne sensors is to identify the electromagnetic radiations from different targets with certain wavelength that ranges from visible $(0.38-0.76 \mu \mathrm{m})$ to microwave $\left(10^{-3} \mathrm{~mm}-1 \mathrm{~m}\right)$. More specifically, the spaceborne sensors measure both energy that is radiated by thermal emission or reflected from radiating objects

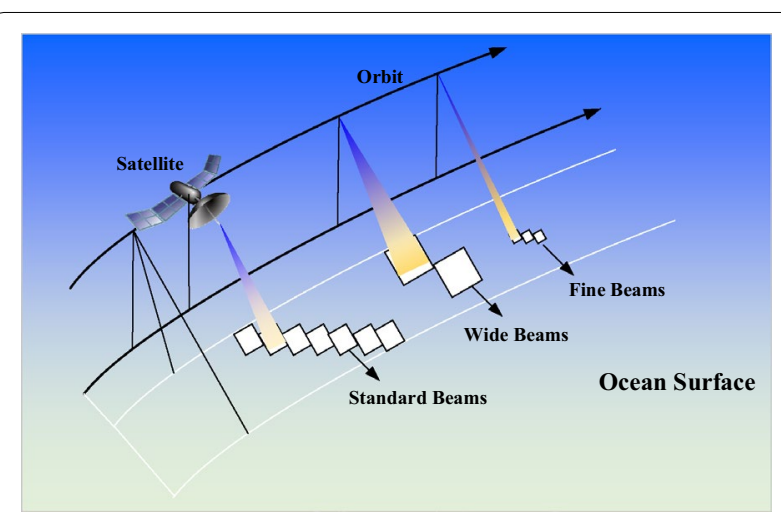

Figure 3 Remote sensing by the satellite

from earth and atmosphere, and from returned scattered signals from the actively transmitted illumination pulses.

There are a variety of space-borne sensors used for observing the global oceans. It is not possible to describe all the sensors designed for satellites here, and thus some versatile sensors, including radiometers, altimeters and scatterometers, whose rationale is representative, are briefly introduced below.

The design objective of the passive radiometer is to measure sea surface temperature (SST), which can be solved by Planck's law which reveals the relationship between thermal emission and the physical temperature of an ideal blackbody. The operational electromagnetic spectrum of radiometers covers from visible to microwave regions, but only specific frequency bands, commonly referred to as the atmospheric windows (3.55-3.93 $\mu \mathrm{m}$ and 10.5-12.5 $\mu \mathrm{m})$ [31], can minimize the atmospheric attenuation of electromagnetic waves, ensuring enough energy returning to the space-borne radiometer. The typical accuracy of infrared-based radiometer is better than $0.3 \mathrm{~K}$ with a resolution of $\sim 1-4 \mathrm{~km}$, while the accuracy of microwave-based measurements ranges from $0.5 \mathrm{~K}$ to $0.8 \mathrm{~K}$, with a coarse resolution of $\sim 25 \mathrm{~km}$ [32].

The primary usage of satellite altimetry is to gain sea surface height (SSH). Additionally, sea level rise, significant wave height and wind speed are also retrieved from this instrument. Generally, altimeter sensors first 
transmit short pulses with a typical duration of nanoseconds, and then detect the returned pulses along with the two-way travel time. With the recorded time, reflected signals and the height of the satellite above a reference ellipsoid, the altimeter height above the sea surface and sea surface height are both computed. Retrieving geophysical parameters, including SST, significant wave height and wind speed, commonly relies on the maximum likelihood estimation and least square methods $[33,34]$. The detailed computational process can refer to the work by $\mathrm{Fu}$ [35]. Typical accuracy of three retrieved parameters are $\sim 0.3 \mathrm{~m}, \sim 3-4 \mathrm{~cm}$ and $\sim 2 \mathrm{~m} / \mathrm{s}$, respectively.

The function of a satellite scatterometer is to measure vector winds on the ocean surface. The typical accuracy of derived wind vectors is $\sim 2 \mathrm{~m} / \mathrm{s}$ in the speed and $\sim 20^{\circ}$ in the direction [32]. According to the backscattering dependence on the radar azimuth, that is, the fact that the backscattered power to the scatterometer is proportional to the sea surface roughness, wind vectors of the ocean surface are retrieved by the geophysical model function in scatterometer terminology, usually at an interval of 24-48 h, which allows routine observation of the oceans. The synthetic aperture radar (SAR) is also an active radar as the scatterometer, but it can provide higher resolution images (within $1 \mathrm{~m}$ ) of the ocean surface compared to scatterometers. More details can refer to Refs. [36, 37].

\subsection{Unmanned Surface Vehicles}

With the experience and technology advances obtained from underwater vehicles, unmanned surface vehicles (USVs), also known as autonomous surface vehicles (ASVs) or autonomous surface crafts (ASCs), play an increasingly important roles in various aspects of marine engineering and scientific research.

The existing type of USVs range from small torpedo size to large unmanned ships, and can be equipped with different onboard sensors and instruments for specialized tasks.

The first USV may date back to World War II in 1944 when Canadian developed the COMOX torpedo for preNormandy invasion, in order to reduce risks to manned forces [38]. Since then, great progress has been made in the development of USVs because of the technology advances in commercial navigation sensors and communication devices, as well as much more importance paid by the US navy for military surveillance, mine sweeping, littoral warfare and anti-terrorism missions [39]. In addition to the military applications, USVs for scientific research or marine engineering are also much required, such as oil spilling detection, bathymetric mapping, offshore pipeline survey, meteorological survey and water ecological study [40-42].
According to the existing prototypes of USVs, the hull of the craft can be classified roughly into catamaran [43, 44], kayak [45, 46] and rigid inflatable types [47]. Catamaran and kayak types are frequently used due to their convenient installation. The good stability, payload capacity and ease of deck access make catamaran-type USVs a compelling choice for academic USVs [48]. Kayak-type USVs are easy to fabricate, and they are often designed by directly modifying existing manned surface vehicles, thus reducing both development periods and cost. Rigid inflatable hulls are suitable for military applications primarily because they have greater endurance and payload capacity to carry larger fuel tanks. Most USVs are submerged with only a mast for communication and air intake protruding above water, while $C \& C$ Technologies and ASV Ltd. cooperatively developed a novel semisubmersible USV with only a single hull, which allows for utilizing internal combustion propulsion systems [49]. The motion of existing USVs are usually controlled by the combination of the rudder and propeller/water jet. As for catamaran-type USVs, they can also be controlled by differential propulsion when steering. In most cases, USVs are designed to be the under-actuated mode for cost savings, that is, not all the degree-of-freedoms (DOFs) of USVs can be actively controlled; consequently, it would be difficult to precisely control USVs along pre-defined mission trajectories, particularly at bad sea states. The global positioning system (GPS), wireless communication unit and inertial measurement unit (IMU) are the basic sensor suite equipped with the USVs. Some additional sensors, such as radar, sonar and camera, are optionally adopted according to the requirement of tasks.

Traditional USVs are known as their strong survey capabilities at designated regions, however, some emerging USVs are going beyond energy limitations by harvesting solar, wind or wave energy. The typical case is the development of Wave Glider, developed by Liquid Robotics Inc. [50, 51]. The Wave Glider USV is propelled by the purely mechanical conversion of ocean wave energy into forward thrust and uses solar panels to power onboard electronics, which only consumes $0.7 \mathrm{~W}$ averagely for navigation, communication and control systems. Moreover, to harvest wind energy, some USVs were designed like a sailboat, utilizing sail to convert the wind energy to the mechanical energy for moving [52, 53].

Fully-autonomous operation of USVs is always limited due to the loss risks in the present applications. Instead, the semi-autonomy mode, such as teleoperation by the crew onshore, has been favored over the fully-autonomy in the past years. As a sustained observing platform (Wave Glider), the USVs provide opportunities to complement fixed moored buoys, underwater vehicles, Lagrangian drifters, and some seafloor observatories. 
Meanwhile coordinated groups of USVs could be directed to intensively study real-time conditions in the ocean with a lower cost compared to mooring arrays. Future development of USVs tends to utilize artificial intelligence technology and high-level sensors to extend the capabilities in more complicated missions without human intervention. It should be noted that the use of USVs must be ready to interact with all manner of shipping, that is, the on-going research programs should address the technical questions posed by the intersection of USVs and the nautical rules of the road [48].

\section{Profile Observation Technologies}

\subsection{Argo Floats}

Argo (Array for Real-time Geostrophic Oceanography) is an international program with global network of autonomous profiling floats to sample temperature, salinity and current data of the upper oceans $[54,55]$. The first prototype of Argo floats was proposed by Swallow in 1955 when the first deep current measurement was gained by a neutrally buoyant float [56]. With the advances in technologies, the first Argo float was deployed in 1999 and now most Argo data are available within $24 \mathrm{~h}$ of acquisition. There are two Argo Global Data Assembly Centers (GDACs) responsible for completing dataset for users without limitation, and they are established in the USA and France, respectively. The major uses of Argo data are to quantitatively describe the changing state of the upper ocean and the patterns of ocean climate variability at different time scales, complement the satellite data for interpretation of altimetric sea surface height variability, improve initialization of ocean-atmosphere climate models, and forecast whether and climate changes [1]. Additionally, marine safety and transport, fishery management, offshore industry, and even military defense also are the application fields of Argo data.

So far, there has been more than 4000 active Argo floats operating in the oceans and they are from over 30 nations (Figure 4). The Argo project recommends that

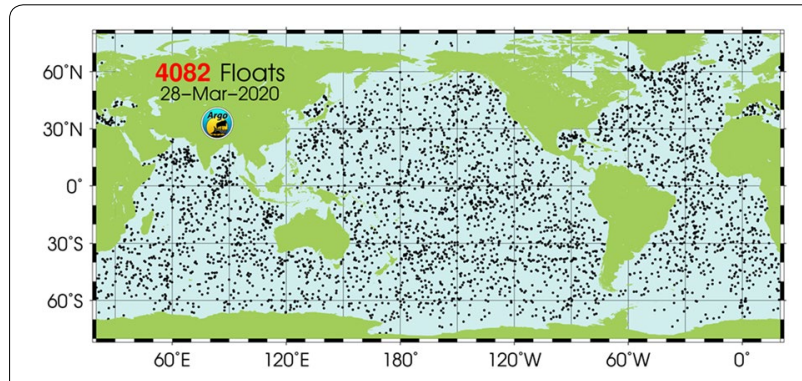

Figure 4 Argo float distribution (Figure courtesy from Argo home page: http://www.argo.ucsd.edu/) the array of floats space of $3 \times 3$ (nominal $300 \mathrm{~km} \mathrm{spa-}$ tial resolution), and drift at a nominal depth of $1000 \mathrm{~m}$ (known as the parking depth) to give uniform velocity field and profile to $2000 \mathrm{~m}$ to capture essential variability, all of which rely on the comprehensive consideration of spatial statistics from satellite altimetry, WOCE hydrographic sampling, studies from XBT (temperature probe) networks, and knowledge of ocean variability [57]. A typical operation cycle of Argo floats is about 10 days and follows these four steps: (1) be launched from the surface vessel and dive to the parking depth, (2) drift 8-10 days and descent to the depth of $2000 \mathrm{~m}$, (3) rise over a period of approximately 6 hours to the sea surface, collecting oceanographic variables during the ascend process, and (4) transmit recorded data to satellites and then descend back to begin another cycle. This process can refer to Figure 5.

The rise and sinking motion (buoyance adjustment) of Argo floats are achieved by pumping fluid into an external bladder and deflating the bladder, and most Argo floats utilize GPS for geolocation when they surface, and nearly $80 \%$ of floats utilize Iridium communications and the rest use Argos communications.

To gain reliable long-term measurements from Argo floats, the drift of sensors must be corrected. Correcting by expert experience and comparing with standard instruments, moored buoys, or ship-based data were proved to be feasible [58]. In addition, utilizing sensors from the same manufacturer, even the same batch, is effective to reduce the anomalies in measurements.

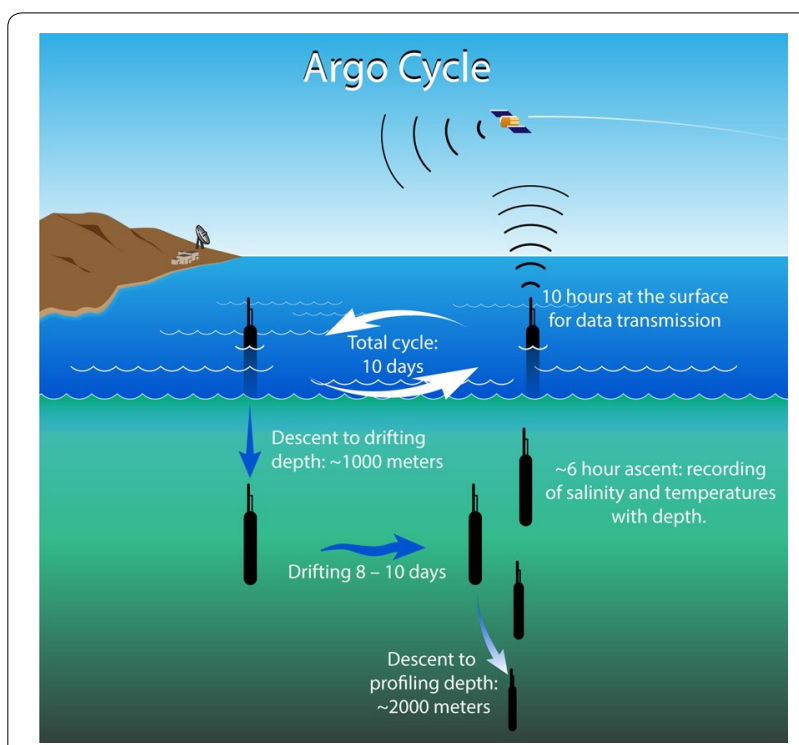

Figure 5 The operational cycle of Argo floats (Figure courtesy from Argo home page: http://www.argo.ucsd.edu/) 
Following the above operations, the error can be reduced within acceptable ranges in most cases.

Although the Argo project has made a great accomplishment in the past two decades, there are still unsolved problems and possibilities to evolve and expand. While mapping monthly and seasonal ocean changes at large scale, the vigorous ocean turbulence caused by the boundary current regimes would arise greater error in Argo data compared to those regions with relatively gentle sea states, due to the sparsely spatial resolution of Argo array $[59,60]$. Additionally, more dense sampling is called for in equatorial regions, marginal seas, and even ice-covered regions, all of which either produce significant impacts on global climate or ocean changes, or are regionally important to natural resource and trade. Some of these suggested initiatives are now underway via test deployments or regional pilot arrays [61-63]. In addition to deploying floats in unexplored regions, equipment upgrade from software to hardware is the future trend of Argo developments. As stated before, Argo floats were initially designed to be deployed to a maximum depth of $2000 \mathrm{~m}$. However, with the investigation going further, several studies have shown that the ocean below $2000 \mathrm{~m}$ contributed a significant portion of the total water column in the rise of sea level and hear content, particularly at the depth below $3000 \mathrm{~m}$ in the high southern latitudes $[64,65]$. To sample the abyssal ocean, the USA, Japan, France, China, etc. are pushing the limits of depth of the autonomous floats to $4000 \mathrm{~m}$ or $6000 \mathrm{~m}$ levels [55, 66], exploiting the capabilities of operational observing systems to provide comprehensive information for the advances of the GOOS.

Beyond deployments in deeper oceans, the developments of biogeochemical sensors bring the possibilities to measure key biogeochemical variables [67], such as dissolved oxygen, nitrate, chlorophyll, and $\mathrm{pH}$, because they have small physical size and characteristics of low power consumption, and can be equipped with floats conveniently. Utilizing these data, oceanographers would gain a deeper understanding of the impacts of ocean circulations on biogeochemical processes. Additionally, the station-keeping capabilities are critical to the floats because of the drifting performance would cause an uneven distribution of the float arrays, reducing the data quality. This problem is now being addressed by some current model-based strategies that autonomously adjust the depth of the floats $[68,69]$.

\subsection{Underwater Gliders}

A compelling vision of autonomous sampling network by autonomous underwater gliders was proposed by Stommel in 1989 [70], in order to complement the current approaches to resolve features at shorter temporal and spatial scales, and now this technology is mature in various scientific missions and observing systems. The development of underwater gliders stretches over 25 years and was given a boost by strategic funding from the US Office of Naval Research, leading to three types of underwater gliders, developed in parallel by three competing groups: Spray [71], developed by Scripps Institution of Oceanography and Woods Hole Oceanographic Institution; Seaglider [72], developed by the University of Washington; Slocum [73], developed by Webb Research. Although there are novel aspects to each of the resulting designs and several new glider types are also existing, these three gliders are the most frequently used for observation tasks. Early ocean missions using gliders were only capable of maintaining several days. From 2000 to 2003, the technology has been progressed to allow deploying multiple gliders, which served as a fraction of Autonomous Ocean Sampling Network (AOSN), laying a good basis of coordinated networking [74]. With the advances in glider technology, the durations of gliders are now extended to multiple months even an annual scale, operating in various previously unexplored or sparsely temporal-spatial sampling regions. Gliders began with a basic sensor suite for conductivity, temperature and depth (CTD), and then be progressively added with dissolved oxygen, fluorescence, acoustics, nitrate and backscatter sensors [7577], all of which are similar (but not restricted) to that equipped in Argo floats, expanding the sampling capabilities of gliders in physical, biogeochemical and acoustic parameters. Table 2 provides major applications of the underwater gliders, as well as their estimated variables.

The underwater glider is essentially an autonomous float but with ability to sample across strong lateral gradients (such as eddies, boundary currents and episodic events) by shifting its buoyancy and battery mass, and utilizing wings to project vertical motion into the horizontal, while Argo floats are always drifting with currents. When used efficiently, gliders deliver profiles for per-profile costs that are roughly equivalent to floats, but finely spaced along track way points due to the nature of the platform. In general, underwater gliders are moving slowly for long-duration operations since the energy loss to hydrodynamic drag is proportional to glider speed through the water cubed, and each glider has an optimum speed to achieve a maximum range if with known hydrodynamic characteristics. Prospectively, gliders are designed to be capable of addressing challenges encountered when planning observations in remote, difficult-toaccess sites, and harsh operating conditions, and are also envisioned as low-cost and simple observatories to operate, enabling flexible deployment in quantity.

Typical operational modes of underwater gliders include virtual moorings (station-keeping) [87, 88], 
Table 2 Applications in observing oceanographic features

\begin{tabular}{ll}
\hline Oceanographic features & Measured/estimated variables \\
\hline Boundary currents [78] & Cross-stream density gradients and depth-average currents \\
Upwelling [79] & Temperature, salinity, and fluorescence \\
Internal waves [80] & Vertical velocity \\
Fronts [81] & Temperature and salinity gradients \\
Eddies [82] & Conductivity, salinity, pressure, dissolved oxygen and fluorescence \\
Algal bloom [83] & CTD, dissolved oxygen, fluorescence, photosynthetically active radiation, \\
Zooplankton abundance/fish activities [84,85] & and optical backscattering \\
Sediment transport and resuspension [86] & Acoustic backscatter and fluorescence \\
\hline
\end{tabular}

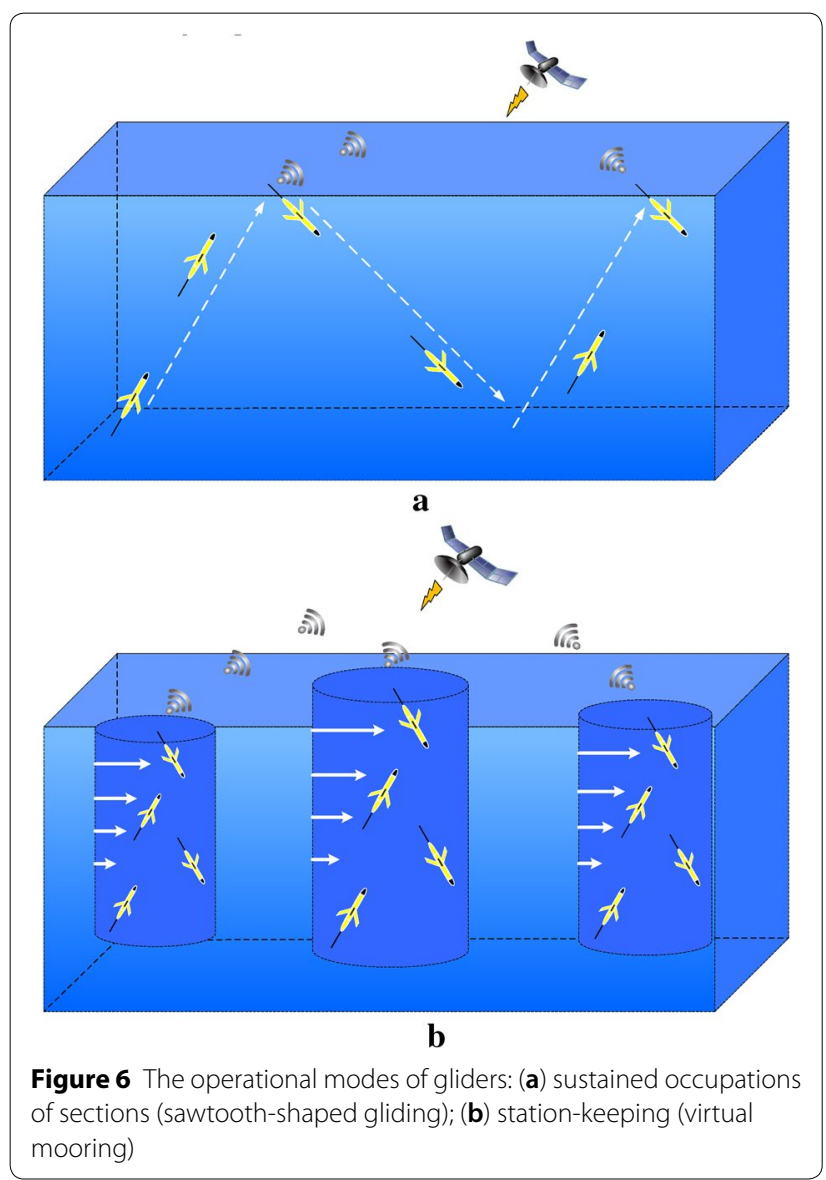

sustained occupations of sections [81], and as survey tools in limited-duration process studies [89]. The schematic diagrams of the operational modes are shown in Figure 6 . The first operational mode of gliders is prospective to replace expensive moored buoys at designated sites to sample water column and air-sea coupled parameters for whether prediction, and the latter two applications lead the design toward persistent sampling of the oceanic mesoscale, resolving scales of kilometers and hours, with the monthly endurance required to characterize climate variability. In general, when the glider accomplishes a cycle of mission, it would surface to transmit the recorded data to shore crew via Iridium satellite systems by antennas housed in a tail fin, tail string, or in a wing. However, loss of communication with satellites is inevitable somewhat in bad sea conditions, and thereby gliders should have adequate memory for data buffering and storage [90]. Gliders can geolocate themselves by GPS when surface, and are allowed to be reprogrammed to adjust their mission trajectories and flight parameters simultaneously. Even under ice-covered regions where GPS is unavailable, gliders can locate themselves if equipped with acoustic modules, such as the ultrashort base line (USBL) system. This approach not only extends the exploration range of gliders but also provides opportunities for users to intervene glider missions in real-time, with enhanced working efficiency, especially in some coordinated group missions.

Although gliders have demonstrated great progress in diverse scientific missions, efforts to improve reliability, ease of use, accessible parameters, and deployment periods (better planning strategies, enhanced battery capabilities or harvesting renewable energy [91]) and depth should also be invested to broaden access to the technology. Additionally, integration of gliders in the currently operating observing arrays would be the future trend of developments because working in combination with other technologies such as floats and moored buoys, would improve the distribution density both in temporal or spatial scale.

\section{Seafloor Observation Technologies 4.1 Cabled Seafloor Observatories}

The ocean sciences are entering a new era where oceanographers can observe the oceans by in situ robotics instruments and sensor networks. Although autonomous underwater platforms, satellite transmission, and acoustic data links have made remarkable progress in providing 
new data acquisition methods in the past decades, scientific or military sensors, instruments and platforms that require high power, high data rates or continuous access to the seafloor are still out of reach of these technologies [92], facilitating the establishment of cabled seafloor observatories (CSOs). The CSOs are the infrastructure that provides large amounts of electrical power and twoway high bandwidth to access and control sensor, instrument and platform networks connecting to junction boxes at the seafloor, and they are usually operating at annual scales with a high level of reliability. Figure $7 \mathrm{dem}$ onstrates a tree type topology of the CSO. The modalities of the CSOs range from several simple sensors across the oceans to the systems utilizing multiple nodes along the route, which depend on the specific needs of the scientific community. Despite considerable advances of the non-contact mateable connectors [93], the electrooptical mateable connectors (physically connected) are still the most commonly used to connect nodes and sensors/instruments/platforms. The operation of connecting devices with the junction boxes is usually achieved by a remotely-operated vehicle (ROV).

Some of the early coastal CSOs were designed with an alternating current (AC) power-feeding system [94], which can be readily derived from the local utility and allow the efficiency of high-voltage transmission [95]. However, this kind of power-feeding systems are not suitable for the CSOs that require long-distance power transmission because of the reactive components caused by the parasitic effects of the cables. The use of a constant current $(\mathrm{CC})$ or a constant voltage $(\mathrm{CV})$ power source is the primary choice of the recently developed CSOs, which use direct current with one conductor and seawater return. A CC power-feeding system is robust against cable shunt faults because its power is usually supplied from both ends of the cable even if the cable is shunted to seawater at one point [96], whereas a CV power-feeding

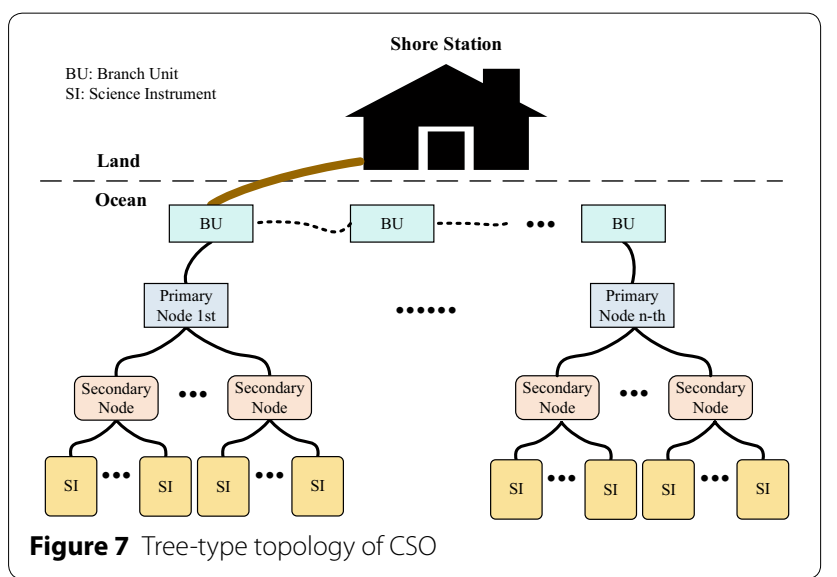

system would break down with any shunt fault in the system even if it can provide up to twice the power of a $\mathrm{CC}$ system. Thus, the CC power source are commonly selected for CSOs used for tsunami and seismic early warning.

Submarine telecommunication systems are used for high-capacity data transmission over long distances (with optical fiber amplifiers), and they are designed to be incorporated in the cable of CSOs at intervals of $60-150 \mathrm{~km}$ [9]. The average lifetime of telecommunication systems is up to 25 years without internal faults and failures. A branch unit (BU) is routinely used for connecting the backbone cable with the scientific node through a spur cable [97]. The BU will isolate the fault from the backbone or the spur cable by opening the inner switches, ensuring the normal operation of the rest of the system. In general, the length interval of the BUs along the cable ranges from tens of kilometers to hundreds of kilometers, and the lengths of spur cables would be several to tens of kilometers.

CSOs are now in operation or under construction from several countries or unions, primarily including Japan (dense ocean-floor network system for earthquakes tsunamis-DONET [98], and national research institute for earth science and disaster prevention seafloor network-NIED [99], versatile eco-monitoring network by under-cable system-VENUS [100], and advanced real-time earth monitoring network in the area-ARENA [101]), Canada (north east Pacific time-series undersea networked experiments-NEPTUNE [102], and Victoria experimental network under the sea-VENUS [103]), the USA (Monterey accelerated research system-MARS [104], ALOHA cabled observatory-ACO [105], national science foundation's ocean observatories initiative's regional scale nodes-RSN [106]), Europe (European sea observatory network-ESONET [107]), and China (South China sea seafloor observation network-SCSSON [108]). Table 3 summarizes the primary uses of some of the existing CSOs.

The cabled seafloor observatories yet have received international recognition, leading increasingly emerging technologies and developers to expand the capabilities and coverage of existing systems. Because of the expensive cables (for broad coverage) and sensors/instruments/ devices, the establishments of the future cabled seafloor observatories need to be developed by extensive cooperation from different sectors or countries, in order to reduce the average economic burden posed on each developer. Additionally, taking advantage of the submarine telecommunication cables that were already retired or were soon to be retired would reduce the development cost greatly, and the typical cases were the re-use in $\mathrm{H}_{2} \mathrm{O}$ and $\mathrm{ACO}$ projects $[105,110]$. The development 
Table 3 Existing cabled seafloor observatories

\begin{tabular}{|c|c|c|c|}
\hline Project & Installation time & Developer & Objective \\
\hline LEO-15 [94] & 1996 & $\mathrm{WHOI}$ & $\begin{array}{l}\text { Long-term ecosystem observing off the central coast of } \\
\text { New Jersey }\end{array}$ \\
\hline HUGO [109] & 1997 & The University of Hawaii & $\begin{array}{l}\text { Studying undersea volcanism and associated phenom- } \\
\text { ena at Loihi, the newest volcano of the Hawaiian chain }\end{array}$ \\
\hline $\mathrm{H} 2 \mathrm{O}[110]$ & 1998 & $\begin{array}{l}\text { WHOI, The University of Hawaii, and Margus, Inc, } \\
\text { etc. }\end{array}$ & Studying seismology \\
\hline VENUS & 1999 & JAMSTEC & Eco-monitoring and fit for manned submersible \\
\hline MVCO [111] & 2000 & $\mathrm{WHOI}$ & $\begin{array}{l}\text { Studying coastal atmospheric and oceanic processes of } \\
\text { Martha's Vineyard Coast }\end{array}$ \\
\hline DONET [98] & 2006 & JAMSTEC & Precise earthquake and tsunami monitoring \\
\hline VENUS [103] & 2006 & The University of Victoria & $\begin{array}{l}\text { Understanding biological, chemical, and physical } \\
\text { processes of the coastal waters of southern Vancouver } \\
\text { Island }\end{array}$ \\
\hline NEPTUNE $[97,102]$ & 2007 & The University of Victoria & $\begin{array}{l}\text { Studying hydrothermal systems, gas hydrates, the } \\
\text { coupling between physical and biological systems, the } \\
\text { dynamics of deep-sea benthic ecosystems, the inshore } \\
\text { physical and biological oceanography, etc. }\end{array}$ \\
\hline MARS [104] & 2008 & Monterey Bay Aquarium Research Institute & Long-term measurements in deep benthic environments \\
\hline $\mathrm{ACO}[105]$ & 2011 & The University of Hawaii & $\begin{array}{l}\text { Investigating temporal dynamics in biology, physics, and } \\
\text { chemistry }\end{array}$ \\
\hline ESONET $[107,112]$ & 2011 & Europe & $\begin{array}{l}\text { Understanding the role of Arctic Ocean for climate } \\
\text { changes, long-term observation on mud-volcano erup- } \\
\text { tions in the Norwegian margin, studying biogeochemi- } \\
\text { cal processes of the Porcupine Abyssal Plain, etc. }\end{array}$ \\
\hline $\operatorname{RSN}[106]$ & 2012 & The University of Washington, etc. & $\begin{array}{l}\text { Serving future science needs and technological } \\
\text { advances }\end{array}$ \\
\hline NIED [99] & 2014 & $\begin{array}{l}\text { National Research Institute for Earth Science and } \\
\text { Disaster Prevention (Japan) }\end{array}$ & $\begin{array}{l}\text { Monitoring earthquake, tsunami and vertical crustal } \\
\text { deformation }\end{array}$ \\
\hline SCSSON [108] & 2016 & Zhejiang University, Tongji University, etc. & $\begin{array}{l}\text { Studying ocean dynamics and biogeochemical pro- } \\
\text { cesses, and preventing disasters, etc. }\end{array}$ \\
\hline
\end{tabular}

of embedded cables (also known as smart cables [113]), aims to make some of the observatories compact without loss of utility and has a bright future serving the global ocean observing networks [114]. For instance, when monitoring tsunami and earthquake, the related sensor suites, which usually include pressure, acceleration and temperature sensors can be included in cable repeaters, with little or no impacts on the operation of the telecommunications systems. The design of cabled seafloor observatories must be driven by the demands of the scientific staff who will use the platforms and data, ensuring that the systems can be widely employed to serve specific scientific missions. In addition, designing an installation which delivers the required performance and is maintainable at a reasonable cost are also essential to the application of the systems developed.

\subsection{AUVs}

Autonomous underwater vehicles (AUVs) are unmanned underwater robots with strong maneuverability to carry out diverse oceanographic missions autonomously, such as geological exploration [115], oil spill detection [116], bathymetry, and thermocline tracking [117], which are early originally achieved by towed arrays or manned vehicles. AUV designs usually include torpedo-like, hovering, catamaran, open frame, and bionic types. Their sizes range from human portable to tons levels, and the working depth ranges from several meters to $11000 \mathrm{~m}$ [118]. Notwithstanding a wide range of AUVs, torpedolike AUVs are the most commonly used due to their better hydrodynamic characteristics that enable longer operation periods.

Navigation accuracy has great impacts on the safe operation and recovery of the AUV, as well as the value of the data collected by the AUV. Different from terrestrial navigation, the absence of GPS signals underwater arises a difficult challenge for AUV navigation. Utilizing acoustic beacons at known positions can provide ground-truth reference to locate AUVs underwater (but ranges are limited), otherwise the AUV should rely on the on-aboard sensor suite, usually including a compass and a Doppler velocity logger (DVL) or an inertial navigation system (INS) to perform dead reckoning [119]. The hydrodynamic model of an AUV can be used to predict the 
speed, being capable of providing acceptable accuracy in localization in calm water [120]. These methods are useful, but the performance is essentially limited because of the time-accumulating error. Recent studies have shown that the simultaneous localization and mapping (SLAM) method gives a bounded localization error either on land or underwater with loop closure strategies [121-123], However, environments with high turbidity and feature sparsity on the seafloor arise challenging to SLAM-based methods.

Compared to gliders and floats, the major advantage of the AUV is its better maneuverability that allows for tracking specific oceanographic features in the case of currents, with rapid control response and accurate localization performance. One should note that although observing the features on the seafloor is a vital application scenario, AUVs can also perform well in observing water column or features within a limited range of depths, such as tracking thermocline, internal waves and algal bloom. Most of the oceanographic features are dynamic, and thus require the AUV to timely response to the ambient changes. The behavior that the AUV adjusts its observation strategies in real time to track, map and sample the target with a high level of onboard situational awareness, is known as the "autonomy". Feature scales would affect the number of survey platforms needed to be involved in observing missions. For instance, the mesoscale oceanographic features, which usually cover ranges from $10 \mathrm{~km}$ to $100 \mathrm{~km}$, are expected to use a fleet of coordinated AUVs to investigate, rather than a single AUV, in order to gain a more synoptic and cohesive dataset [124].

Artificial intelligence is a critical characteristic of the future AUVs. Without the opportunities to transmit a mass of data back to the operators, the onboard intelligent system must be capable of accomplishing the mission series, including sampling, characterizing events, decision-making and eventually executing. This behaviorbased autonomy should enable the AUV to response to both predictable and unpredictable sensor events. Taking advantage of a fleet of autonomous gliders is important to enhance the capabilities in observing the oceanographic features because the vehicles in a team can cooperate through feedback control to coordinate their motion as a mobile and reconfigurable sensor array, responding efficiently to variabilities, scales, and conditions in the environments. Furthermore, glider groups can improve the richness of collected information, accuracy in feature detection and tracking, as well as the robustness of their decisions to uncertainty and failures [125].

\subsection{Hadal Landers}

The hadal zone refers to the oceans with the depth ranging from $6000 \mathrm{~m}$ to $11000 \mathrm{~m}$, approximately accounting for the deepest $45 \%$ of the oceanic depth range and host active and diverse biological communities [126]. The hadal zone is almost comprised of trenches, which are formed by tectonic subduction. The first sampling attempts at the hadal zones were conducted using trawl and grab methods during the 1950s on the Danish Galathea and Russian Vitjaz expeditions [127]. Because of the insufficient technologies to access to the hadal depths in the past few decades, the gathered information regarding the hadal biology and the ecology was sparse and uncoordinated.

Recently technological advances of the hadal exploration was remarkable, especially in the development of free-falling hadal landers, which provided new opportunities to fill the knowledge gap of the deepest marine environment on Earth. The landers have flexible configuration that can be sized and configured based on the specific requirements from oceanographic scientists. The deployment of hadal landers only needs appropriatelysized and seaworthy vessels, which can be found in a smaller harbor closer to the operation location, consuming a more modest cost compared to traditional large and specialized vessels. In addition, hadal landers can be deployed at the seafloor for an entire year or much longer if needed and precede a ROV or manned submersible operations to determine a specific area of interest [128]. It is even more attractive that hadal landers are simpler to design and fabricate compared to AUVs, ROVs or manned submersibles which involve the complicated sealing issues of dynamic components.

A lander is roughly composed of three subsystems, including the delivery system, control and energy system, and the scientific payload. The primary design goal of the delivery system is to carry and protect the scientific payload within a frame. The buoyance assembly (syntactic foam or glass spheres) and ballast are usually coupled to topside and underside of the frame respectively, in order to maintain the stability of the lander during its free-falling periods. The ballast weights can be released by the acoustic signal from the surface and the resulting positive buoyance would drive the lander to rise. For a lander to be recovered successfully, the time-delay or actively controlled ballast jettison device can be equipped for emergency cases, such as failures in the primary acoustic releases [129]. Affected by the currents during descending, the lander may deviate from the pre-set benthonic region, in which the lander cannot be accessed by acoustic communications caused by the blocks from the hadal trenches. To solve this problem, Chen proposed an inversion calculation method to determine the lander position 
with an accuracy of $20 \mathrm{~m}$ [130]. The control subsystem is used for making decisions of triggering sampling, recording data (e.g., from scientific sensors and cameras), processing data, responding to emergency, and controlling the motion of landers (e.g., release ballast). Rechargeable lithium battery pack is the primary power source for most designs of landers. The output voltages of batteries are regulated via DC-DC modules to supply power for different scientific payloads. The equipped scientific payloads of existing landers include CTD sensors, dissolved oxygen sensors, water and sediment samplers, baited traps, in situ microorganism enrichment and fixation devices, etc. These biogeochemical data would provide opportunities to find more discoveries at hadal depths.

Alfie and Jonah landers from Japan and the UK [127], Alpha lander from the USA [128], and Tianya, Haijiao and Wanquan landers from China [131] were the typical lander prototypes developed in recent years, all of which collected valuable samples during the expeditions, renewing international interest in observing the deepest oceanic environments. The next step technologically is to upgrade the landers with more scientific instruments to measure or sample more oceanographic features, not only restricted within biology and ecology. Additionally, maintaining the pressure and temperature (i.e., high fidelity) of the collected samples is critical to accurately analyze the elements of samples and life processes of hadal creatures [132]. Although the hadal landers have lower cost compared to those AUVs, ROVs and manned submersibles working at the similar depths, the existing observations and samplings only remain in regional scales due to the limited number of landers. Thus, how to reasonably deploy and distribute the landers at hadal zones is still challenging and needs widespread contributions from all over the world.

\section{Combination of the Static and Dynamic Observing Technologies: Future Trend}

\subsection{Current Status of AUV Docking Technologies}

Docking technology serves as a "bridge" to connect the static and dynamic observations, facilitating expanded coverage in spatial and temporal, and enhanced endurance of the ocean observatories. In addition to returning data via satellite, the data can be returned by guiding the AUV to a docking station fixed on a mooring system [133] or connecting to a cabled seafloor observing network [134] (Figure 8). When docked, the AUV returns data, downloads a new mission plan and recharges battery for extended working periods in a wired (via a physically connected connector) or wireless (inductive) way [135-137]. The mooring-based docking station requires the surface buoy to transmit the returned data from the AUV via Iridium satellite, and the CSO-based docking

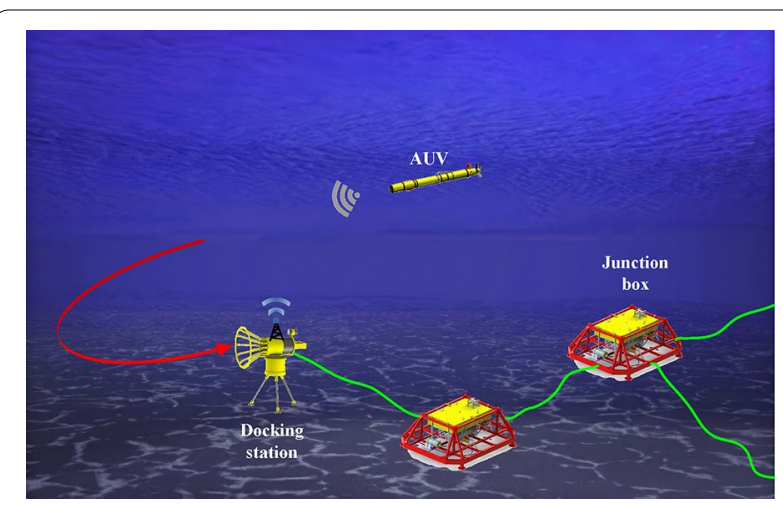

Figure 8 Combination of AUVs and docking stations

station returns data directly via seafloor cables connecting to the shore station in real time, bridging the static and dynamic observations in a more effective way. For the docking process the AUV is guided into a cone usually using a USBL positioning system or a combination of USBL and machine vision if the AUV is able to recognize the lights housed on the docking station [138]. During this process, the AUV continuously adjust its pose to correct the horizontal and vertical position/attitude error until the AUV aligns with the cone axis and enters the cone eventually.

Taking advantage of rotatable-cone docking stations would reduce the difficulties in AUV docking operations because the cone aligned with the current direction enables the AUV to run against the current to increase the pose correction periods without loss of the controllability and interference from lateral currents. The primary challenge to utilize rotatable-cone docking stations is the rapidly accumulating fouling as both plants and animals attach themselves. Even dealt with antifouling paints, the docking station inevitably accumulate large masses that eventually interferes with the rotatable components because of the limited lifetime of the antifouling paints used; therefore, the deployment of rotatable-type docking stations might last for only months. Combing with the fixed-cone docking stations, the AUV can complete the docking operation by online planning an anti-current trajectory based on the estimation of the current vector. Even if missing the docking station, the AUV can still dock by repeated attempts. In addition to the cone-based docking operations, the AUV can dock to a seabed base as the landing of an aircraft to the aircraft carrier [139], whereby the AUV doesn't need to dock with a specified heading angle, remarkably reducing the difficulties in terminal pose adjustment. However, this method arises the design challenges in battery charging and lock devices. 


\subsection{Prospects of Ocean Observing Systems with the Docking Technology}

A notable challenge of the present docking technology is the high price of the sensor suite for AUV recovery, and this problem may be addressed by some emerging but lower-cost localization methods. SLAM techniques build a map of an unknown environment and localize the AUV in the map, whereby the localization error of the AUV can be bounded within a limited range. The optical camera or imaging sonar (e.g., relatively inexpensive mechanical-scanned sonar) can be the front-end sensor of the AUV to sense the seafloor features that centered on the docking station with a certain radius, which is promising up to over $10 \mathrm{~km}$. With a forward-looking imaging sonar, the AUV can not only locate by matching with the prior seafloor map, but also adjust the pose based on the detected docking station in the sonar images when the distance relative to the docking station is short, as shown in Figure 9a. Although the optical camera-based SLAM method has better accuracy, it is always affected by the turbidity and illuminance of the water. Range-only SLAM is another potential SLAM method for AUV docking operations [140]. Simply stated, the AUV locates itself by repeatedly measuring the distance

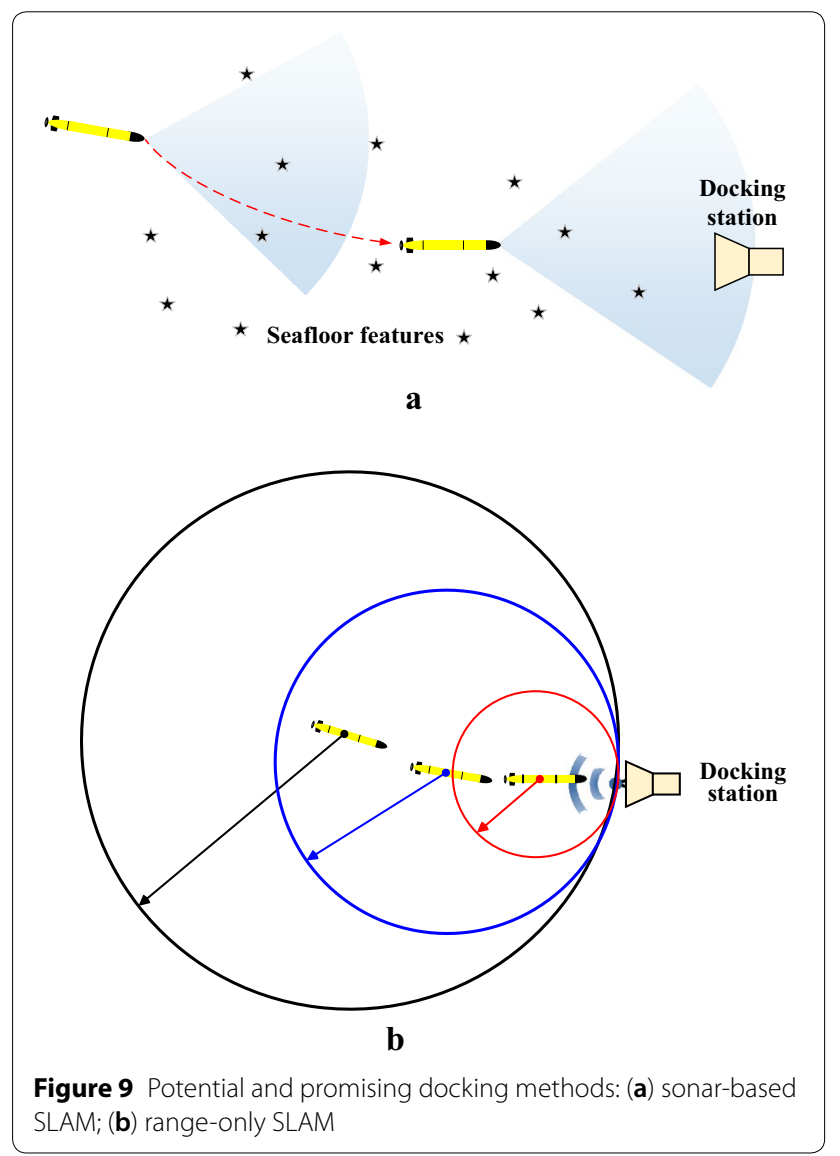

relative to the acoustic beacon (docking station) at different locations and determining the intersection points of the circles with the radii equal to the measured distance, as shown in Figure 9b. With the estimated displacement between two AUV locations, heading angle of the AUV, and the intersection point of circles, the AUV locations can be well-determined. If with multiple beacons (docking stations), the localization accuracy of the AUV can be improved further. A major consideration of this method is the treatment of the outliers, and the price of the required acoustic modules is lower than the commonlyused USBL positioning system.

To our best knowledge, the power capabilities of the present underwater wireless charger ranges from dozens of watts to over one kilowatt, and the charging process follows the "CC-CV" rule essentially. For a docking station to be versatile, it is supposed to provide different charging power levels up to hundreds of kilowatts to support a wide range of unmanned underwater vehicles; thus, the AUV charging parameters, such voltage, current and the charging rule should be designed to be easily modified, such as sending a modification data package to the docking station. The fast charging technologies for the automobiles are gradually mature for terrestrial applications. Integrating this technology to AUV charging systems would be critical to reduce the charging periods, which usually last for several to over ten hours under the "CC-CV" rule. For the non-torpedo type of AUVs, it is better to design a planar charging (docking) station, and thus the AUV can dock and charge on the platform without designing a specific-shaped entrance for the AUV docking station.

The commonly used wireless communications between AUVs and docking stations are based on WiFi, which transmits data with a rate up to several megabytes per second underwater (limited by the distance between antennas). If the AUV collects a large amount of data (e.g., keeps sampling over a month), the data returning periods might last for several hours, which are even longer than the charging periods. One of the solutions is to add data transmission modules, but it would increase the design cost and complexity in both software and hardware. Optical communication is a promising method for high-speed data transmission, and its maximum data transmission rate can be over $15 \mathrm{Gbps}$ in underwater environments. For some cases that the AUV needs to return data but does not need recharging, a pair of omnidirectional optical transmitter and receiver can be used for underwater stations; thus, the AUV should only travel near the optical receiver without docking operations. Optical data transmission distance can be over $100 \mathrm{~m}$ maximumly with a transmission rate of $1-5 \mathrm{Mbps}$ (depends on the water quality). 
Sustained ocean observations require persistent energy supply. Except the cabled seafloor observatories, most observing systems are equipped with battery pack to provide energy. However, the energy of the battery is always limited and the docking technology can only support the observatories that are not far away from the offshore regions. Harvesting renewable energy is an inexorable trend for the future development of oceanic observatories. Solar energy, and the wave and thermal energy from the oceans are the most commonly harvested for the recently developed systems, ensuring persistent operations of the oceanic observatories.

Figure 10 provides a conception of the future ocean observing system, which combines the existing observatories by the docking technology and is supported by the renewable energy. For coastal observing systems, the dynamically and statically collected data can be firstly returned to the junction boxes and then to the shore station. For coping with data collected by gliders and floats, the observatories can surface and transmit data to the satellites. To persistently work, the gliders and floats harvest the thermal gradient energy created by the temperature difference between the sea surface and seafloor, and the AUV can be guided to the docking station for recharging. For offshore observing systems, transmitting data to satellites may be the most appropriate choice. Short-wave communications may be possible in the future. The offshore seafloor docking stations cannot be powered by the junction boxes, but are instead powered by battery pack, which can be recharged by harvesting wave energy and receiving energy from the solar charging vehicles (SCVs). The SCVs absorb solar energy at the sea surface and then descend to seek docking stations to transmit power to them. In addition to deploying docking stations on the seafloor, deploying docking stations at a near-sea-surface depth is also promising; therefore, the docking station is powered by the USV (e.g. wave gliders), which harvests solar and wave energy as power source. This way is more suitable for the AUVs that observe the upper water column. For offshore gliders or profilers, deploying a docking station with a vertically upward entrance would be useful to recover and recharge them.

\section{Conclusions}

The oceans are integral to life, weather, climate and biogeochemical cycles, representing rich sources of oil, food, minerals and renewable energy. This paper reviews the typical observing technologies and proposes a blueprint of the future ocean observing systems based on docking technology. Although increasingly mature observing technologies can enhance resource uses and management, and improve the understanding of the oceans, the

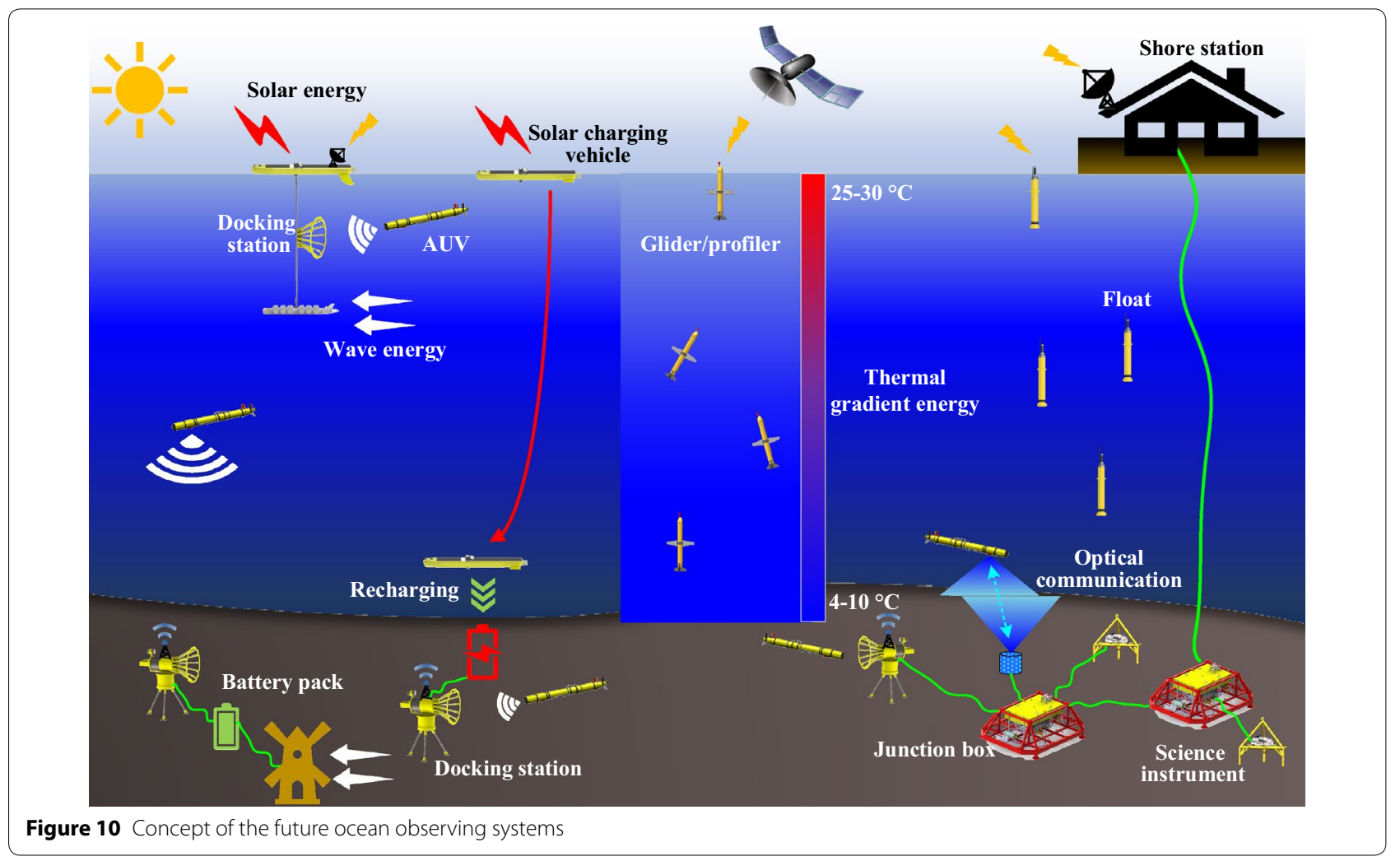


advances of existing observing systems have been constrained by flat funding and limited cooperation among present users. Engaging end users across society, discovering potential users in respects of commerce, national defense, climate changes and renewable energy, and bringing together users with shared values would be the critical steps in the future development of the Global Ocean Observing System (GOOS), which has now primarily focused on scientific understanding of ocean processes and the ocean's role in climate changes. More importantly, this new partnership should incorporate influential organizations in technologies or reputation, enabling closer engagement with the private sector, colleges, universities, research institutes, governments, and other groups.

\section{Acknowledgements}

Not applicable.

\section{Authors' Contributions}

$M L$ wrote the manuscript and CY reviewed the article and provided the modification suggestions. Both authors read and approved the final manuscript.

\section{Authors' Information}

Mingwei Lin, born in 1991, is currently a postdoctoral researcher at State Key Laboratory of Fluid Power and Mechatronic Systems, Zhejiang University, China. He received his doctoral degree from Zhejiang University, China, in 2019. His research interests include AUV docking technology, underwater contactless charging technology and marine robots for deep-sea observation and exploration.

Canjun Yang, born in 1969, is currently a professor at State Key Laboratory of Fluid Power and Mechatronic Systems, Zhejiang University, China. He received his doctoral degree from Zhejiang University, China, in 1997. His research interests include ocean observing systems and human-machine intelligence technologies.

\section{Funding}

Supported in part by the Marine S\&T Fund of Shandong Province (Grant No. 2018SDKJ0211), in part by the Fund of Platform for Technical Innovation Ningbo Research Institute of Zhejiang University (Grant No. NRI-ZJU-2019001), and in part by the Fundamental Research Funds for the Central Universities (Grant No. 2019XZZX003-07).

\section{Competing Interests}

The authors declare that they have no competing interests.

\section{Author Details}

1 State Key Laboratory of Fluid Power and Mechatronic Systems, Zhejiang University, Hangzhou 310027, China. ${ }^{2}$ Pilot National Laboratory of Marine Science and Technology (Qingdao), Qingdao 266000, China. ${ }^{3}$ Ningbo Research Institute, Zhejiang University, Ningbo 315100, China.

Received: 12 November 2019 Revised: 28 February 2020 Accepted: 31 March 2020

Published online: 15 April 2020

\section{References}

[1] Argo Project Office: Why do we need Argo? 2020[2020-03-29]. http://argo. ucsd.edu/.

[2] K Suyehiro, H Mikada, K Asakawa. Japanese seafloor observing systems: Present and future. Marine Technology Society Journal, 2003, 37(3): 102-114.
[3] Michael J Mcphaden. The tropical atmosphere ocean array is completed. Bulletin of the American Meteorological Society, 1995, 76(5): 739-741.

[4] J D Woods. The world ocean circulation experiment. Nature, 1985, 6011(314): 501-511.

[5] World Ocean Circulation Experiment (WOCE). 2020[2020-03-29]. https:// www.jodc.go.jp/goin/adcp.html.

[6] Thomas C Malone. The coastal module of the Global Ocean Observing System (GOOS): an assessment of current capabilities to detect change. Marine Policy, 2003, 27(4): 295-302.

[7] GEO:GROUPEARTHOBSERVATIONS.2020[2020-03-29].http://www.earth observations.org/geoss.php.

[8] Earth Observing Laboratory (EOL): Tropical Ocean - Global Atmosphere (TOGA) and Coupled Ocean Atmosphere Response Experiment (COARE). 1992[2020-03-29]. https://www.eol.ucar.edu/field_projects/togacoare.

[9] Arthur B Baggeroer, Bruce M Howe, Peter N Mikhalevsky, et al. Ocean observatories: An engineering challenge. The Bridge, 2018: 18-34.

[10] R Cole, J Kinder, Chun Lin Ning, et al. "Bai-Long": A TAO-hybrid on RAMA. Oceans, 2011: 1-10.

[11] S Aracri, M Borghini, D Canesso, et al. Trials of an autonomous profiling buoy system. Journal of Operational Oceanography, 2016, 9(Sup 1): 176-184.

[12] Robert A Weller. Observing surface meteorology and air-sea fluxes. Observing the Oceans in Real Time, 2018: 17-35.

[13] Sébastien P Bigorre, Robert A Weller, James B Edson, et al. A surface mooring for air-sea interaction research in the gulf stream Part II: Analysis of the observations and their accuracies. Journal of Atmospheric and Oceanic Technology, 2013, 30(3): 450-469.

[14] Claudine Hauri, Seth Danielson, Andrew M P Mcdonnell, et al. From sea ice to seals: A moored marine ecosystem observatory in the Arctic. Ocean Science Discussions, 2018: 1-16.

[15] Andrew Hamilton. Buoy technology. Ocean Engineering, 2016: 937-962.

[16] David Elwood, Solomon C Yim, Joe Prudell, et al. Design, construction, and ocean testing of a taut-moored dual-body wave energy converter with a linear generator power take-off. Renewable Energy, 2010, 35(2): 348-354.

[17] Akira Nagano, Iwao Ueki, Takuya Hasegawa, et al. Ocean-atmosphere observations in Philippine sea by moored buoy. Oceans, 2018: 1-6.

[18] D J Maxwell, T Mettlach, B Taft, et al. The 2010 National Data Buoy Center (NDBC) mooring workshop. IEEE, 2010.

[19] R Venkatesan, J K Lix, A Phanindra Reddy, et al. Two decades of operating the Indian moored buoy network: significance and impact. Journal of Operational Oceanography, 2016, 9(1): 45-54.

[20] Russ E Davis. Drifter observations of coastal surface currents during CODE: The method and descriptive view. Journal of Geophysical Research: Oceans, 1985, 90(3): 4741-4755.

[21] Semyon A Grodsky, Rick Lumpkin, James A Carton. Spurious trends in global surface drifter currents. Geophysical Research Letters, 2011, 38(10): 1-6.

[22] Rick Lumpkin, Luca Centurioni, Renellys C Perez. Fulfilling observing system implementation requirements with the global drifter array. Journal of Atmospheric and Oceanic Technology, 2016, 33(4): 685-695.

[23] Pearn P Niiler, Andrew S Sybrandy, Kenong Bi, et al. Measurements of the water-following capability of holey-sock and TRISTAR drifters. Deep Sea Research Part 1: Oceanographic Research Papers, 1995, 42(11): 1951-1964.

[24] Rick Lumpkin, Mayra Pazos. Measuring surface currents with Surface Velocity Program drifters: the instrument, its data, and some recent results. Lagrangian Analysis and Prediction of Coastal and Ocean Dynamics, 2005.

[25] Scott D Woodruff, Steven J Worley, Sandra J Lubker, et al. ICOADS Release 2.5: extensions and enhancements to the surface marine meteorological archive. International Journal of Climatology, 2011, 31(7): 951-967.

[26] Erik van Sebille, Stephanie Waterman, Alice Barthel, et al. Pairwise surface drifter separation in the western Pacific sector of the Southern Ocean. Journal of Geophysical Research: Oceans, 2015, 120(10): 6769-6781. 
[27] Yu-Chia Chang, Ruo-Shan Tseng, Peter C Chu, et al. Observed strong currents under global tropical cyclones. Journal of Marine Systems, 2016, 159: 33-40.

[28] Rick Lumpkin, Semyon A Grodsky, Luca Centurioni, et al. Removing spurious low-frequency variability in drifter velocities. Journal of Atmospheric and Oceanic Technology, 2013, 30(2): 353-360

[29] Guillaume Novelli, Cédric M Guigand, Charles Cousin, et al. A biodegradable surface drifter for ocean sampling on a massive scale. Journal of Atmospheric and Oceanic Technology, 2017, 34(11): 2509-2532.

[30] Arthur P Cracknell, Costas A Varotsos. Editorial and cover: Fifty years after the first artificial satellite: from Sputnik 1 to ENVISAT. International Journal of Remote Sensing, 2007, 28(10): 2071-2072.

[31] E Paul Mcclain. Multiple atmospheric-window techniques for satellitederived sea surface temperatures. Oceanography from Space, 1981: 73-85.

[32] T Misra, R Sharma, R Kumar, et al. Ocean remote sensing: Concept to realization for physical oceanographic studies. Observing the Oceans in Real Time, 2018: 165-202.

[33] G Picardi, R Seu, S G Sorge, et al. Bistatic model of ocean scattering. IEEE Transactions on Antennas and Propagation, 1998, 46(10): 1531-1541.

[34] David T Sandwell, Walter H F Smith. Retracking ERS-1 altimeter waveforms for optimal gravity field recovery. Geophysical Journal International, 2005, 163(1): 79-89.

[35] Lee-Lueng Fu, Eds Anny Cazenave. Satellite altimetry and earth sciences: a handbook of techniques and applications. Elsevier, 2000.

[36] Federico Raspini, Andrea Ciampalini, Sara Del Conte, et al. Exploitation of amplitude and phase of satellite SAR images for landslide mapping: The case of Montescaglioso (South Italy). Remote Sensing, 2015, 7(11): 14576-14596.

[37] Thierry Toutin, Laurence Gray. State-of-the-art of elevation extraction from satellite SAR data. ISPRS Journal of Photogrammetry and Remote Sensing, 2000, 55(1): 13-33.

[38] Volker Bertram. Unmanned surface vehicles - A survey. Skibsteknisk Selskab, Copenhagen, Denmark. 2008: 1-14.

[39] S J Corfield, J M Young. Unmanned surface vehicles - game changing technology for naval operations. Advances in Unmanned Marine Vehicles, 2006

[40] Marco Bibuli, Massimo Caccia, Lionel Lapierre, et al. Guidance of unmanned surface vehicles: Experiments in vehicle following. IEEE Robotics \& Automation Magazine, 2012, 19(3): 92-102.

[41] Ru-Jian Yan, Shuo Pang, Han-Bing Sun, et al. Development and missions of unmanned surface vehicle. Journal of Marine Science and Application, 2010, 9(4): 451-457.

[42] Jiucai Jin, Jie Zhang, Feng Shao, et al. A novel ocean bathymetry technology based on an unmanned surface vehicle. Acta Oceanologica Sinica, 2018, 37(9): 99-106.

[43] Yingjie Deng, Xianku Zhang, Guoqing Zhang, et al. Parallel guidance and event-triggered robust fuzzy control for path following of autonomous wing-sailed catamaran. Ocean Engineering, 2019, 190: 106442.

[44] Seok-In Sohn, Jung-Hwan Oh, Yeon-Seung Lee, et al. Design of a fuelcell-powered catamaran-type unmanned surface vehicle. IEEE Journal of Oceanic Engineering, 2015, 40(2): 388-396.

[45] Pranay Agrawal, John M Dolan. COLREGS-compliant target following for an Unmanned Surface Vehicle in dynamic environments. IEEE, 2015.

[46] Paul Mahacek, Christopher A Kitts, Ignacio Mas. Dynamic guarding of marine assets through cluster control of automated surface vessel fleets. IEEE/ASME Transactions on Mechatronics, 2012, 17(1): 65-75.

[47] Amit Motwani. A survey of uninhabited surface vehicles. Marine and Industrial Dynamic Analysis, School of Marine Science and Engineering, Plymouth University, 2012

[48] Justin E Manley. Unmanned surface vehicles, 15 years of development. Oceans, 2008

[49] S Phillips, D Hook, H Young. Remote deployment of commercial and military sensors at sea. Proceedings of UDT Europe 2008, Nexus Media, Glasgow, Scotland, June 2008.

[50] J Manley, S Willcox. The wave glider: A new concept for deploying ocean instrumentation. IEEE Instrumentation \& Measurement Magazine, 2010, 13(6): 8-13.

[51] Tom Daniel, Justin Manley, Neil Trenaman. The wave glider: enabling a new approach to persistent ocean observation and research. Ocean Dynamics, 2011, 61(10): 1509-1520.
[52] Yong Ma, Yujiao Zhao, Jiantao Diao, et al. Design of sail-assisted unmanned surface vehicle intelligent control system. Mathematical Problems in Engineering, 2016: 1-13.

[53] X Q Zhou, L L Ling, J M Ma, et al. The design and application of an unmanned surface vehicle powered by solar and wind energy. 2015 6th International Conference on Power Electronics Systems and Applications (PESA), 2015: 1-10.

[54] Dean H Roemmich, Russ Davis, Stephen Riser, et al. The Argo Project: Global ocean observations for understanding and prediction of climate variability. Oceanography, 2000, 2(7).

[55] Stephen C Riser, Howard J Freeland, Dean Roemmich, et al. Fifteen years of ocean observations with the global Argo array. Nature Climate Change, 2016, 6(2): 145-153.

[56] J C Swallow. Some further deep current measurements using neutrallybuoyant floats. Deep Sea Research, 1957, 4(1953): 93-104.

[57] A Sterl, B Klein, V Thierry, et al. Argo - A decade of progress. 2009.

[58] Lijing Cheng, Jiang Zhu, Rebecca Cowley, et al. Time, probe type, and temperature variable bias corrections to historical expendable bathythermograph observations. Journal of Atmospheric and Oceanic Technology, 2014, 31(8): 1793-1825.

[59] Sylvia T Cole, Cimarron Wortham, Eric Kunze, et al. Eddy stirring and horizontal diffusivity from Argo float observations: Geographic and depth variability. Geophysical Research Letters, 2015, 42(10): 3989-3997.

[60] Meghan F Cronin. Monitoring ocean-atmosphere interactions in western boundary current extensions. 2010.

[61] Dongliang Yuan, Zhichun Zhang, Peter C Chu, et al. Geostrophic circulation in the tropical north pacific ocean based on Argo profiles. Journal of Physical Oceanography, 2014, 44(2): 558-575.

[62] Katsuro Katsumata, Hiroshi Yoshinari. Uncertainties in global mapping of Argo drift data at the parking level. Journal of Oceanography, 2010, 66(4): 553-569.

[63] John M Toole, Richard A Krishfield, Mary-Louise Timmermans, et al. The Ice-Tethered Profiler: Argo of the Arctic. Oceanography, 2011, 24(3): 126-135.

[64] Sarah G Purkey, Gregory C Johnson. Antarctic bottom water warming and freshening: Contributions to sea level rise, ocean freshwater budgets, and global heat gain. Journal of Climate, 2013, 26(16): 6105-6122.

[65] Gregory C Johnson, Sarah G Purkey, John L Bullister. Warming and freshening in the Abyssal Southeastern Indian Ocean. Journal of Climate, 2008, 21(20): 5351-5363.

[66] Serge Le Reste, Vincent Dutreuil, Xavier André, et al. "Deep-Arvor": A new profiling float to extend the Argo observations down to 4000-m depth. Journal of Atmospheric and Oceanic Technology, 2016, 33(5): 1039-1055.

[67] Emil Vassilev Stanev, Sebastian Grayek, Hervé Claustre, et al. Water intrusions and particle signatures in the Black Sea: a Biogeochemical-Argo float investigation. Ocean Dynamics, 2017, 67(9): 1119-1136.

[68] Martina Troesch, Steve Chien, Yi Chao, et al. Autonomous control of marine floats in the presence of dynamic, uncertain ocean currents. Robotics and Autonomous Systems, 2018, 108: 100-114.

[69] Ryan N Smith, Van T Huynh. Controlling buoyancy-driven profiling floats for applications in ocean observation. IEEE Journal of Oceanic Engineering, 2014, 39(3): 571-586.

[70] Henry M Stommel. The Slocum mission. Oceanography, 1989, 1(2): 22-25.

[71] J Sherman, R E Davis, W B Owens, et al. The autonomous underwater glider "Spray". IEEE Journal of Oceanic Engineering, 2001, 26(4): 437-446.

[72] C C Eriksen, T J Osse, R D Light, et al. Seaglider: a long-range autonomous underwater vehicle for oceanographic research. IEEE Journal of Oceanic Engineering, 2001, 26(4): 424-436.

[73] D C Webb, P J Simonetti, C P Jones. SLOCUM: an underwater glider propelled by environmental energy. IEEE Journal of Oceanic Engineering, 2001, 26(4): 447-452.

[74] D L Rudnick, R E Davis, C C Eriksen, et al. Underwater gliders for ocean research. Marine Technology Society Journal, 2004, 38(2): 73-84.

[75] Amandine Schaeffer, Moninya Roughan, Emlyn M Jones, et al. Physical and biogeochemical spatial scales of variability in the East Australian Current separation from shelf glider measurements. Biogeosciences, 2016, 13(6): 1967-1975

[76] David K Mellinger, Sharon L Nieukirk, Sara L Heimlich, et al. Passive acoustic monitoring in the Northern Gulf of Mexico using ocean 
gliders. The Journal of the Acoustical Society of America, 2017, 142(4): 2533.

[77] Douglas R Zemeckis, Micah J Dean, Annamaria I Deangelis, et al. Identifying the distribution of Atlantic cod spawning using multiple fixed and glider-mounted acoustic technologies. ICES Journal of Marine Science, 2019.

[78] Russ E Davis, William S Kessler, Jeffrey T Sherman. Gliders measure western boundary current transport from the South Pacific to the Equator. Journal of Physical Oceanography, 2012, 42(11): 2001-2013.

[79] J Karstensen, T Liblik, J Fischer, et al. Summer upwelling at the Boknis Eck time series station (1982 to 2012)-a combined glider and wind data analysis. Biogeosciences, 2014, 11(13): 3603-3617.

[80] Daniel L Rudnick, T M Shaun Johnston, Jeffrey T Sherman. High-frequency internal waves near the Luzon Strait observed by underwater gliders. Journal of Geophysical Research: Oceans, 2013, 118(2): 774-784.

[81] Mar M Flexas, Martina ITroesch, Steve Chien, et al. Autonomous sampling of ocean submesoscale fronts with ocean gliders and numerical model forecasting. Journal of Atmospheric and Oceanic Technology, 2018, 35(3): 503-521.

[82] J P Martin, C M Lee, C C Eriksen, et al. Glider observations of kinematics in a Gulf of Alaska eddy. Journal of Geophysical Research, 2009, 114(C12): 1-19.

[83] Sandy J Thomalla, Marie-Fanny Racault, Sebastiaan Swart, et al. Highresolution view of the spring bloom initiation and net community production in the Subantarctic Southern Ocean using glider data. ICES Journal of Marine Science: Journal du Conseil, 2015, 72(6): 1999-2020.

[84] Camille M L S Pagniello, Megan A Cimino, Eric Terrill. Mapping fish chorus distributions in southern California using an autonomous wave glider. Frontiers in Marine Science, 2019, 6.

[85] Jesse R Powell, Mark D Ohman. Changes in zooplankton habitat, behavior, and acoustic scattering characteristics across glider-resolved fronts in the Southern California Current System. Progress in Oceanography, 2015, 134: 77-92.

[86] Scott Glenn, Clayton Jones, Michael Twardowski, et al. Glider observations of sediment resuspension in a Middle Atlantic Bight Fall Transition Storm. Limnology and Oceanography, 2008, 53(5): 2180-2196.

[87] Evan B Clark, Andrew Branch, Steve Chien, et al. Station-keeping underwater gliders using a predictive ocean circulation model and applications to SWOT calibration and validation. IEEE Journal of Oceanic Engineering, 2018: 1-14.

[88] Puzhe Zhou, Canjun Yang, Shijun Wu, et al. Designated area persistent monitoring strategies for hybrid underwater profilers. IEEE Journal of Oceanic Engineering, 2019: 1-15.

[89] Russ E Davis, Naomi E Leonard, David M Fratantoni. Routing strategies for underwater gliders. Deep Sea Research Part II: Topical Studies in Oceanography, 2009, 56(3-5): 173-187.

[90] David Meyer. Glider technology for ocean observations: A review. Ocean Science Discussions, 2016: 1-26.

[91] Qingchao Xia, Yanhu Chen, Canjun Yang, et al. A new model of phase change process for thermal energy storage. International Journal of Energy Research, 2018, 42(12): 3877-3887.

[92] B M Howe, F K Duennebier, R Lukas. The ALOHA cabled observatory. SEAFLOOR OBSERVATORIES: A New Vision of the Earth from the AbysS, Favali P, Beranzoli L, De Santis A, Berlin, Heidelberg: Springer Berlin Heidelberg, 2015: 439-463.

[93] Tianlei Wang, Dejun Li, Canjun Yang, et al. Non-contact wet mate connectors for subsea observation networks. Oceans 2016 MTS/IEEE Monterey, 2016.

[94] N C Forrester, Roger Stokey, C von Alt, et al. The LEO-15 long-term ecosystem observatory: design and installation. Oceans, 1997.

[95] B M Howe, H Kirkham, V Vorperian. Power system considerations for undersea observatories. IEEE Journal of Oceanic Engineering, 2002, 27(2): 267-274.

[96] Kenichi Asakawa, Junichi Kojima, Jun Muramatsu, et al. Current-tocurrent converter for scientific underwater cable networks. IEEE Journal of Oceanic Engineering, 2007, 32(3): 584-592.

[97] Ting Chan, Chen-Ching Liu, Bruce M Howe, et al. Fault location for the NEPTUNE power system. IEEE Transactions on Power Systems, 2007, 22(2): 522-531.
[98] K Kawaguchi, Y Kaneda, E Araki. The DONET: A real-time seafloor research infrastructure for the precise earthquake and tsunami monitoring: OCEANS MTS/IEEE. Kobe: 20081-4.

[99] T Kanazawa. Japan Trench earthquake and tsunami monitoring network of cable-linked 150 ocean bottom observatories and its impact to earth disaster science. IEEE International Underwater Technology Symposium, 2013: 1-5.

[100] K Kawaguchi, H Momma, R Iwase. VENUS PROJECT-submarine cable recovery system. Oceans, 1998: 448-452

[101] K Asakawa, J Muramatsu, J Kojima, et al. Feasibility study on power feeding system for scientific cable network ARENA. The 3rd International Workshop on Scientific Use of Submarine Cables and Related Technologies, IEEE, 2003: 307-312.

[102] Chris R Barnes, Mairi Mr Best, Adam Zielinski. The NEPTUNE Canada regional cabled ocean observatory. Technology (Crayford, England), 2008, 3(50).

[103] R Dewey, VTunnicliffe. VENUS: future science on a coastal mid-depth observatory. The 3rd International Workshop on Scientific Use of Submarine Cables and Related Technologies, IEEE, 2003: 232-233.

[104] R G Henthorn, B W Hobson, P R Mcgill, et al. MARS benthic rover: In-situ rapid proto-testing on the Monterey Accelerated Research System. Oceans, 2010: 1-7.

[105] B M Howe, R Lukas, F Duennebier, et al. ALOHA cabled observatory installation. IEEE, 2011

[106] Peter Yinger, Philip Tennant, John Reardon, et al. Commissioning of a system that terminates on the seafloor. Oceans, 2013: 1-6.

[107] R Person, L Beranzoli, C Berndt, et al. ESONET: An European sea observatory initiative. Oceans, 2008: 1-6.

[108] F Lu, H Zhou, X Peng, et al. Technical preparation and prototype development for long-term cabled seafloor observatories in Chinese marginal seas. SEAFLOOR OBSERVATORIES: A New Vision of the Earth from the Abyss, Favali P, Beranzoli L, De Santis A. Berlin, Heidelberg: Springer Berlin Heidelberg, 2015: 503-529.

[109] F K Duennebier, D W Harris, J Jolly, et al. HUGO: the Hawaii undersea geo-observatory. IEEE Journal of Oceanic Engineering, 2002, 27(2): 218-227.

[110] Rhett Butler, Alan D Chave, Frederick K Duennebier, et al. H2O-Hawaii-2 observatory pioneers opportunities for remote instrumentation in ocean studies. Eos, Transactions American Geophysical Union, 2000, 15(81): 157-163.

[111] TC Austin, J B Edson, W R Mcgillis, et al. A network-based telemetry architecture developed for the Martha's Vineyard Coastal Observatory. IEEE Journal of Oceanic Engineering, 2002, 27(2): 228-234.

[112] R Person, P Favali, H A Ruhl, et al. From ESONET multidisciplinary scientific community to EMSO novel European research infrastructure for ocean observation. SEAFLOOR OBSERVATORIES: A New Vision of the Earth from the Abyss, Favali P, Beranzoli L, De Santis A, Berlin, Heidelberg: Springer, 2015: 531-563.

[113] SMART Cables for Observing the Global Ocean: Science and Implementation. Frontiers in Marine Science, 2019, 6(424): 1-27.

[114] Rhett Butler. The scientific and societal case for the integration of environmental sensors into new submarine telecommunication cables. Joint Task Force on Green Cables ITU/WMO/UNESCO/IOC publication, 2014

[115] C Kunz, C Murphy, R Camilli, et al. Deep sea underwater robotic exploration in the ice-covered Arctic ocean with AUVs. IEEE, 2008.

[116] A R Diercks, V L Asper, M Woolsey, et al. Site reconnaissance surveys for oil spill research using deep-sea AUVs. MTS, 2013.

[117] Yanwu Zhang, J G Bellingham, M A Godin, et al. Using an autonomous underwater vehicle to track the thermocline based on peak-gradient detection. IEEE Journal of Oceanic Engineering, 2012, 37(3): 544-553.

[118] A D Bowen, D R Yoerger, C Taylor, et al. The Nereus hybrid underwater robotic vehicle for global ocean science operations to $11,000 \mathrm{~m}$ depth. Oceans, 2008: 1-10.

[119] J J Leonard, A Bahr. Autonomous underwater vehicle navigation. Springer Handbook of Ocean Engineering, Springer, 2016: 341-358.

[120] Mingwei Lin, Canjun Yang, Dejun Li. Hybrid strategy based model parameter estimation of irregular-shaped underwater vehicles for predicting velocity. Robotics and Autonomous Systems, 2020, 127: 103480.

[121] Mingwei Lin, Canjun Yang, Dejun Li. An improved transformed unscented FastSLAM with adaptive genetic resampling. IEEE Transactions on Industrial Electronics, 2019, 66(5): 3583-3594. 
[122] Jie Li, Michael Kaess, Ryan M Eustice, et al. Pose-graph SLAM using forward-looking sonar. IEEE Robotics and Automation Letters, 2018, 3(3): 2330-2337.

[123] Mingwei Lin, Canjun Yang, Dejun Li, et al. Intelligent filter-based SLAM for mobile robots with improved localization performance. IEEE Access, 2019, 7: 113284-113297

[124] Jimin Hwang, Neil Bose, Shuangshuang Fan. AUV adaptive sampling methods: A review. Applied Sciences, 2019, 9(15): 3145-3174.

[125] Naomi Ehrich Leonard. Cooperative vehicle environmental monitoring. Springer Handbook of Ocean Engineering, Springer, Cham, 2016: 441-458.

[126] Alan J Jamieson, Toyonobu Fujii, Daniel J Mayor, et al. Hadal trenches: the ecology of the deepest places on Earth. Trends in Ecology \& Evolution, 2010, 25(3): 190-197.

[127] Alan J Jamieson, Toyonobu Fujii, Martin Solan, et al. HADEEP: Freefalling landers to the deepest places on earth. Marine Technology Society Journal, 2009, 43(5): 151-160.

[128] Kevin Hardy, Tim Bulman, James Cameron, et al. Hadal landers: the DEEPSEA CHALLENGE ocean trench free vehicles. Oceans MTS/IEEE - San Diego, 2013: 1-10.

[129] Jun Chen, Qifeng Zhang, Aiqun Zhang, et al. 7000m lander design for hadal research. Oceans - MTS/IEEE Washington, 2014: 1-4.

[130] Chen Han, Qiu Xuelin, He Enyuan, et al. Accurate measurement and inversion for the seafloor positions of Hadal landers. Chinese Journal of Geophysics, 2019, 5(62): 1744-1754.

[131] Jun Chen, Qifeng Zhang, Yunxiu Zhang, et al. Scientific investigation application of hadal landers in the Mariana Trench. Oceans MTS/IEEE Anchorage, 2017: 1-8.
[132] Shi-Jun Wu, Shuo Wang, Can-Jun Yang. Collection of gas-tight water samples from the bottom of the challenger deep. Journal of Atmospheric and Oceanic Technology, 2018, 35(4): 837-844.

[133] D E Frye, J Kemp, W Paul, et al. Mooring developments for autonomous ocean-sampling networks. IEEE Journal of Oceanic Engineering, 2001 26(4): 477-486.

[134] Dejun Li, Yanhu Chen, Jianguang Shi, et al. Autonomous underwater vehicle docking system for cabled ocean observatory network. Ocean Engineering, 2015, 109: 127-134.

[135] Canjun Yang, Mingwei Lin, Dejun Li. Improving steady and starting characteristics of wireless charging for an AUV docking system. IEEE Journal of Oceanic Engineering, 2018: 1-12.

[136] Mingwei Lin, Dejun Li, Canjun Yang. Design of an ICPT system for battery charging applied to underwater docking systems. Ocean Engineering, 2017, 145: 373-381.

[137] Robert S Mcewen, Brett W Hobson, Lance Mcbride et al. Docking control system for a 54-cm-diameter (21-in) AUV. IEEE Journal of Oceanic Engineering, 2008, 33(4): 550-562.

[138] Ri Lin, Dejun Li, Tao Zhang, et al. A non-contact docking system for charging and recovering autonomous underwater vehicle. Journal of Marine Science and Technology, 2019, 24(3): 902-916.

[139] Canjun Yang, Tianlei Wang, Yanhu Chen. Design and analysis of an omnidirectional and positioning tolerant AUV charging platform. IET Power Electronics, 2019, 12(8): 2108-2117.

[140] Edwin Olson, John J Leonard, Seth Teller. Robust range-only beacon localization, IEEE Journal of Oceanic Engineering, 2006, 31 (4): 949-958.

\section{Submit your manuscript to a SpringerOpen ${ }^{\circ}$ journal and benefit from:}

- Convenient online submission

- Rigorous peer review

- Open access: articles freely available online

- High visibility within the field

- Retaining the copyright to your article

Submit your next manuscript at springeropen.com 